\title{
JOGOS DIGITAIS EM LIVROS ILUSTRADOS ELETRÔNICOS: UMA REVISÃO DAS FRONTEIRAS E APLICAÇÕES
}

\section{DIGITAL GAMES IN ELECTRONIC PICTUREBOOKS: A REVIEW OF DELIMITATIONS AND APPLICATIONS}

\author{
Douglas Menegazzi, Me. ${ }^{1}$ \\ Stephania Padovani, Dra. ${ }^{2}$. \\ (1) Universidade Federal de Santa Catarina \\ e-mail: douglasmenegazzi@gmail.com \\ (2) Universidade Federal do paraná \\ e-mail: s_padovani2@yahoo.co.uk
}

E-book, literatura infantil, ambiente virtual de aprendizagem

\begin{abstract}
Este artigo apresenta uma revisão bibliográfica sistemática acerca da inserção de jogos digitais em livros infantis eletrônicos. Para isso, primeiramente foi realizado o levantamento bibliográfico assistemático, onde foram apresentadas definições sobre livro ilustrado de formato eletrônico e jogos digitais enquanto ambientes de aprendizagem e narrativa. A análise apresenta os resultados mais relevantes e pontua as principais contribuições científicas publicadas sobre a temática. Os resultados encontrados têm por finalidade identificar as fronteiras e aplicações entre livros infantis eletrônicos e jogos digitais.
\end{abstract}

\section{E-book, children's literature, virtual learning environment}

This essay presents a systematic bibliographical review about the insertion of digital games in children's e-books. For this, a non-systematic bibliographical survey was accomplished, where definitions of electronic picturebook format and digital games were presented as virtual environments in learning and narrative. The analysis presents the most relevant results and analyzes the main scientific contributions published about this subject. The results are aimed at identifying the delimitations and applications between electronic children's books and digital games

\section{Introdução}

O impacto dos e-books, forma abreviada de "livros eletrônicos" "electronic book" (SARGEANT, 2015), vem estabelecendo mudanças radicais no modelo de habitual de leitura, como também na geração, produção e publicação editorial no país. (MELLO, 2012) As principais mudanças na atividade das editoras ocorrem no desenvolvimento de novos formatos de conteúdos, incluindo vídeos, sons e recursos de interação alinhados aos modernos e-readers, dispositivos eletrônicos de
Realização:
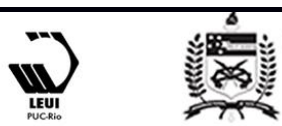


\section{$16^{\circ}$ \\ ERGODESIGN USIHC CINAHPA}

leitura, como tablets e smartphones. (MELLO, 2012) Neste aspexto, Mello (2012) destaca a tendência de "incorporar à experiência da leitura e ao universo dos livros (e-books) mecanismos de interatividade já desenvolvidos em outras áreas que lidam com o formato digital." (MELLO, 2012, p.447)

Linden (2011), Salisbury e Morag (2013), pesquisadores do gênero literário infantil, concordam que o avanço dos processos de produção foi um fator que influenciou muito na receptividade e consagração do livro ilustrado impresso. "Mesmo assim, os criadores não deixam de permanecer sujeitos a certas imposições", como econômicas, de formato, ou limitações editoriais, afirma Linden (2011, p.35). Contudo, a flexibilidade que as mídias digitais favorecem ao livro infantil possibilita recursos que podem atingir experiências sensoriais ainda mais amplas sem um custo de produção e veiculação demasiados caros. (LINDEN, 2011) Mais que isso, "a adoção da tecnologia digital pelo setor editorial desobriga a concepção de um produto limitado a uma lógica sequencial rígida, única, o que confere ao livro digital maior liberdade". (MELLO, 2012, p. 446) Salisbury e Morag (2013), por exemplo, apostam no formato $e$-book como um modelo tecnológico que poderá redefinir o setor editorial voltado ao público infantil.

Contudo, o uso indiscriminado de recursos multimídias nas interfaces dos e-books infantis pode proporcionar estímulos indevidos, desviar a atenção e comprometer a experiência de leitura, advertem Smeets e Bus (2012). Faltam também diretrizes e recomendações para organizar de conteúdo de livros digitais direcionados à literatura infantil (TEIXEIRA, 2015), inclusive no que diz respeito à inclusão de jogos.

Esta pesquisa visa compreender, na aplicação de jogos digitais em $e$-books infantis, quais são as considerações já existentes a partir de outras investigações e estudos deste tema. Para isto, a seguir são apresentados levantamentos bibliográficos para a contextualização e definição de livro infantil ilustrado de formatos eletrônicos, em seguida são pontuadas as características de $16^{\circ}$ Ergodesign - Congresso Internacional de Ergonomia e Usabilidade de Interfaces Humano Tecnológica: Produto, Informações Ambientes Construídos e Transporte

$16^{\circ}$ USIHC - Congresso Internacional de Ergonomia e Usabilidade de Interfaces Humano Computador

CINAHPA | 2017 - Congresso Internacional de Ambientes Hipermídia para Aprendizagem. jogos digitais enquanto ambientes de aprendizagem e narrativa. Na continuidade, é apresentado o método Revisão Bibliográfica Sistemática, descrito a sua aplicação e são apresentados os dados obtidos. Os resultados são apresentam um panorama acerca das fronteiras e aplicações dos jogos em livros eletrônicos para crianças. Esta pesquisa ocorre de forma transdisciplinar entre as áreas de design editorial, design de jogos e literatura infantil, trazendo contribuições para projetos editoriais voltados ao público infantil.

\section{Do livro ilustrado infantil ao e-book}

Uma das principais qualidades do livro ilustrado é permitir e incentivar às crianças, mesmo muito pequenas, a leitura verbal e/ou imagética, tornando possível que elas extraíam diferentes compreensões de uma mesma narrativa.

(NIKOLAJEVA; SCOTT, 2011) Isto fica evidente quando os pequenos leitores pedem para ver, ouvir ou ler as mesmas histórias repetidas vezes. "Na verdade elas não lêem o mesmo livro; elas penetram cada vez mais fundo em seu significado." (idem, p. 15)

O livro infantil tem por característica contar histórias de forma lúdica. (OLIVEIRA, 2008) Nele, as ilustrações e imagens desempenham papel fundamental "para articular aspectos que não podem ser facilmente comunicado por palavras". (HALL, 2012, p.112) Esta configuração revela o status quo do livro ilustrado contemporâneo. (LINDEN, 2011)

Este gênero literário origina-se a partir do século XIX, mediante a formalização sociocultural da infância, com destaque à Inglaterra Vitoriana. (OLIVEIRA, 2008, p. 15) Este período de pósRevolução Industrial contribui com outros fatores cruciais para a configuração do livro ilustrado contemporâneo: a reprodutibilidade gráfica, $\mathrm{o}$ surgimento do mercado de consumo da classe assalariada e a formatação do moderno modelo de escola. (idem). Nesse contexto, segundo Oliveira (2008), o surgimento do livro ilustrado sinalizou a importante mudança social na "visão tradicional da criança como um adulto pequeno" para a
Realização:

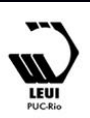




\section{$16^{\circ}$ \\ ERGODESIGN USIHC CINAHPA}

compreensão desta como uma categoria de indivíduo "possuidor de particularidades e necessidades inerentes à sua fase de vida". (OLIVEIRA, 2008, p. 15).

Convém falar do livro ilustrado, portanto, como um dos principais formatos editoriais infantis. (LINDEN, 2011) Isto, porque reúne linguagens dinâmicas e estimulantes por meio de interações entre textos e imagens no espaço fluído e encadeado da página dupla. (LINDEN, 2011, SALISBURY, MORAG, 2013; NIKOLAJEVA, SCOTT, 2011).

Os livros ilustrados infantis têm ganhado uma nova projeção por meio dos modernos suportes eletrônicos de leitura, e-readers. (SALISBURY, MORAG, 2013) Livros infantis de formato $e$-book passam a ser formados por códigos e ganham "materialidade" por meio dos recursos sensoriais dos aparelhos eletrônicos que ocupam.

(FLATSCHART, 2014) Isso tem alterado não apenas a configuração de leitura destas obras eletrônicas, como também o seu processo de produção gráfica (MELLO, 2012) que precisar ser repensado para se comportar como uma interface. (TEIXEIRA, 2015)

\subsection{Formatos de e-books infantis}

E-books (electronic books) podem ser compreendidos enquanto qualquer publicação para leitura em dispositivos eletrônicos (FLATSCHART, 2014). Não obstante, podem ser classificados em formatos, de acordo com os recursos multimídias que apresentam ou de acordo com o suporte eletrônico para o qual foram projetados. (FLATSCHART, 2014, SARGEANT, 2015). Os e-books mais simples, por exemplo, são o de formato de texto, extensão DOC, TXT e $R T F^{1}$, quais podem conter no máximo imagens e links. Os livros de formato PDF são também modelos restritos, incluindo ocasionalmente vídeos e sons. Entre os mais populares, atualmente, estão os formatos EPUB e book app, livro aplicativo. (idem)

\footnotetext{
${ }^{1}$ formatos de extensão de arquivo de texto.
}

$16^{\circ}$ Ergodesign - Congresso Internacional de Ergonomia e Usabilidade de Interfaces Humano Tecnológica: Produto, Informações Ambientes Construídos e Transporte

$16^{\circ}$ USIHC - Congresso Internacional de Ergonomia e Usabilidade de Interfaces Humano Computador

CINAHPA | 2017 - Congresso Internacional de Ambientes Hipermídia para Aprendizagem.

O EPUB surge a partir dos anos 2000, com o lançamento e popularização dos e-readers, como o primeiro formato planejado especificamente para livros eletrônicos. O formato $E P U B$ foi feito para ser suportado na maioria dos e-readers, já que é "destinado a ser um formato de documento de propósito geral". (SARGEANT, 2015, p.45) Contudo, muitos e-books neste formato se limitam às versões estáticas digitalizadas de livros impressos ou livros projetados para serem lidos em leitores simples de poucos recursos multimídia. (idem)

Ao contrário das primeiras gerações de e-books, que eram essencialmente digitalizações de livros impressos, o book app é um novo formato, planejado para usufruir dos mais diferentes recursos disponíveis nos modernos aparelhos tablets e smartphones. (SARGEANT, 2015) Entretanto, os e-books de formato aplicativo são recentes, datam a partir de 2010 (FREDERICO, 2016; SARGEANT, 2015)

Bederson et al. (2009), pesquisador co-fundador do projeto International Children's Digital Library (ICDL), demonstrou problemáticas envolvidas nos primórdios do desenvolvimento de livros para smartphones. $\mathrm{O}$ aplicativo $I C D L$ apresentava-se como uma biblioteca digital que tinha como objetivo difundir e popularizar a leitura de livros eletrônicos, por meio de aparelhos celulares. O projeto iniciado em 2002, apesar de atingir bom resultado, demonstrou deficiências: a resolução e tamanho de tela dos aparelhos na época dificultavam a leitura dos textos e imagens dos livros ilustrados; houve solicitações pelo público por mais recursos, como livros no formato de áudio, porém o projeto ficou limitado à digitalização do livro impresso; o que também demonstrou que o formato da página dupla não se adaptava tão bem à leitura em tela, mesmo possibilitando o "zoom” das páginas.

A partir de 2010 (SARGEANT, 2015, FREDERICO, 2013), o design de livros teve um grande impacto, com o lançamento do Ipad da empresa Apple. A mobilidade e a tela de toque do aparelho tablet proporcionou "um novo tipo de narrativa no formato $e$-book que emerge dessa 


\section{$16^{\circ}$ \\ ERGODESIGN USIHC CINAHPA}

combinação específica de picturebook e tecnologia.” (FREDERICO, 2013, p.1), O “book app" surge, então, como um descritivo de vendas na loja online de aplicativos, App Store, da Apple. (SARGEANT, 2015, p. 46) Como ocorre nos critérios de seleção da Apple Store, livros app devem ir além da digitalização de livros impressos, precisam demonstrar conteúdos especialmente projetados para estes dispositivos eletrônicos. idem) Sargeant (2015) salienta como a empresa Apple no quesito tecnologia tem sido não apenas uma das principais fornecedoras de hardware e software, mas determinante na formação de padrões de design de aplicativos. Tanto que, em seguida o termo book app passa a ser difundido e também à designar livros aplicativos para outras plataformas e sistemas operacionais. (ibidem)

Sargeant (2015, p. 461) defende que $e$-books, no geral, podem ser réplicas de livros impressos e apresentar baixos níveis de interatividade. Contudo, o book app é um formato projetado para combinar "convenções usadas em livros de imagens impressos, design de jogos e filmes animados". (idem)

O Livro infantil app é, portanto, um aplicativo que pode ser baixado via internet diretamente para os aparelhos mobiles, tablets e smartphones. É um software, que possibilita utilizar as capacidades do sistema computacional para o qual ele foi desenvolvido. (FLATSCHART, 2014) Foram projetados como produtos multimídias

(TEIXEIRA, 2015) e multimodais (FREDERICO, 2016) Os livros apps "são geralmente distinguido por características interativas que podem alterar as experiências de um leitor de forma significativa" (SARGEANT, 2015). Os livros ilustrados eletrônicos "parecem ter encontrado a sua plataforma ideal". (FREDERICO, 2016, p.1)

Na comparação entre o $e$-book e o livro ilustrado infantil impresso, uma das mudanças mais significativas abrange seu design, na produção e na gestão de novos conteúdos midiáticos. (MELLO, 2012). Neste sentido, Teixeira (2015) conceitua o livro infantil de formato e-book como multimídia, já que apresenta qualidades multimidiáticas inerentes. O livro eletrônico permite unir diferentes $16^{\circ}$ Ergodesign - Congresso Internacional de Ergonomia e Usabilidade de Interfaces Humano Tecnológica: Produto, Informações Ambientes Construídos e Transporte

$16^{\circ}$ USIHC - Congresso Internacional de Ergonomia e Usabilidade de Interfaces Humano Computador

CINAHPA | 2017 - Congresso Internacional de Ambientes Hipermídia para Aprendizagem.

tipos de recursos midiáticos, como imagens, sons, vídeos, animações e até jogos em um mesmo artefato. Mesmo que o livro ilustrado impresso já apresentasse uma complexa e rica interrelação entre texto, imagem e página dupla (LINDEN, 2011, SALISBURY, MORAG, 2013; NIKOLAJEVA, SCOTT, 201; NECYK, 2007), a "multimídia está relacionada a organização de pelo menos uma mídia estática com uma mídia dinâmica, em ambiente digital e com possibilidades interativas." (TEIXEIRA, 2015, p. 293) Isso torna o e-book infantil uma mídia, ou melhor, multimídia diferenciada do livro impresso.

\subsection{Considerações da leitura em e-books infantis}

Larossa (1996) demarca a experiência de leitura no encontro entre leitor ou ouvinte e o texto (verbal ou imagético). A leitura que ocorre sem o desejo, engajamento, do leitor pode não chegar propriamente a proporcionar uma experiência de leitura, tornando-se meramente informativa. Portanto, a leitura para aquisição de conhecimento se difere de leitura de experiência, que ocorre na motivação espontânea do leitor pela literatura (idem). Apesar de não ser um acontecimento que possa ser controlado, Larossa (1996) argumenta sobre a importância de alguns facilitadores, como o tempo dado à leitura, o ambiente e os sentidos envolvidos no processo.

Acerca do formato do livro ilustrado de formato app, Frederico (2016) problematiza transformações na experiência estética proporcionadas pela "multimodalidade" da literatura infantil. Moraes (2015. pg. 2) afirma que compreender melhor esta "capacidade de produzir discursos que se valem de diferentes modos de significação" pode proporcionar, dentre outros ganhos, maior qualidade na produção de obras literárias para crianças.

Para Teixeira (2015), a organização da gama de recursos multimídia no $e$-book infantil deve ter como fator estruturante a narrativa, o envolvimento que a história provoca no leitor. É necessário, portanto, compreender sistematicamente como e em quais níveis os recursos multimídia, com destaque para os jogos, podem contribuir ao 


\section{$16^{\circ}$ \\ ERGODESIGN USIHC CINAHPA}

processo de leitura infantil dos dispositivos eletrônicos.

A seguir são revisados alguns conceitos e traçadas algumas definições acerca dos jogos digitais como ambientes de aprendizagem e narrativa. Este levantamento teórico apresenta, pela abordagem teórica dos jogos educacionais, alguns interessantes aspectos a serem considerados na análise dos dados coletados e processados pela revisão bibliográfica sistemática proposta.

\section{Jogos digitais como ambientes de aprendizagem e de narrativa}

O homem que brinca, ou Homo ludens tornou possível, por meio dos jogos de sons, significados e símbolos, exercendo o surgimento, segundo Huizinga (2007) da própria escrita, da poesia e da literatura. Este posicionamento define o jogo como supralógico, como algo que está na gênese da cognição, na atividade lúdica da experimentação e da descoberta. Portanto, o jogo não é um produto da civilização, mas é uma categoria primária da vida, um constituinte do próprio ser humano. A própria cultura é um produto do jogo.

(HUIZINGA, 2007)

Kapp (2012), no contexto dos ambientes de aprendizagem dos jogos digitais, pontua os elementos estruturais e salienta importantes características a serem prezadas para que possam compor experiências de aprendizagem eficazes. Apesar dos jogos serem sistemas complexos e incluírem variáveis, a orientação destes elementos pode proporcionar "poderosos resultados de aprendizagem.” (KAPP, 2012, p. 51. Tradução do autor).

Um das características mais importantes aos jogos é a capacidade de abstração de conceitos e eventos reais. (KAPP, 2012, p. 51) A abstração retira da realidade as atividades consideradas enfadonhas e preservar apenas o que é essencialmente importante e atraente. Para Kapp (2012, p. 54) O jogo deve se beneficiar disto, utilizando de elementos que os indivíduos já experimentaram na vida real. Isto permite mais familiaridade e dinamismo e facilita o processo de $16^{\circ}$ Ergodesign - Congresso Internacional de Ergonomia e Usabilidade de Interfaces Humano Tecnológica: Produto, Informações Ambientes Construídos e Transporte

$16^{\circ}$ USIHC - Congresso Internacional de Ergonomia e Usabilidade de Interfaces Humano Computador

CINAHPA | 2017 - Congresso Internacional de Ambientes Hipermídia para Aprendizagem. compreensão das interfaces e mecânicas do jogo. Abstrair também proporciona efeitos mais claramente identificáveis no processo de aprendizagem a qual o jogo se propõe. (idem) .

Os jogos devem possuir objetivos, metas. Para Kapp (2012, p.58), "a simples introdução de um objetivo acrescenta propósito, foco e resultados mensuráveis." A introdução de metas em uma atividade casual pode chegar a torná-la um jogo. Para ambientes de aprendizado, normalmente as metas devem ser bastante claras e se tornam mais atraentes quando possibilitam liberdade e autonomia para os jogadores atingirem-nas. Os objetivos ou submetas geralmente proporcionam, quando cumpridos, elementos de gratificação ao jogador. Estruturas de recompensa são empregadas como motivação. (idem)

O processo do jogo, para Kapp (2012, p.57-58), pode ser ainda mais proveitoso quando proporciona feedback ao jogador, informando, dentre outros aspectos, quão próximo ele está para atingir determinadas metas. O feedback, para Kaap (2012, p. 57) é um elemento que deve ser bem explorado, utilizado com frequiências e intensidades de acordo com os formatos de aprendizagem pretendidos.

Um conjunto de regras também é um dos elementos indispensáveis para qualquer jogo. (KAPP, 2012) Estas, devem ser cuidadosamente projetas para que possibilitem aos jogadores gerenciá-lo. O tempo, outra estrutura intrínseca, é também um instrumento de ordem, limitador, pode fazer parte da meta ou regra, e funciona com um elemento que motiva as ações. (KAPP, 2012)

Os jogos, ainda, possuem níveis. Os níveis que podem ser caracterizados como as fases do jogo, o grau de dificuldade proporcionado ao jogador e, também, como nível de experiência que este atinge. (KAPP, 2012)

A narrativa, embora não esteja presente em todos os jogos, é um ingrediente a ser destacado no intuito do ensino e aprendizagem, afirma Kapp (2012) "O elemento "história" fornece relevância e significado para a experiência. Ele fornece
Realização:

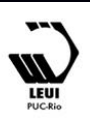




\section{$16^{\circ}$ \\ ERGODESIGN USIHC CINAHPA}

contexto para a aplicação de tarefas." (KAPP, 2012, p. 63. Tradução do autor) Para o autor (idem), a combinação entre jogos de vídeo, por exemplo, e a narrativa pode fornecer uma história que motiva o jogador e estimula a aprendizagem. "Adicionar elementos do jogo e envolver o aluno na história tornando a aprendizagem ainda mais poderosa e memorável". (KAPP, 2012, p. 64. Tradução do autor)

Um jogo instrucional, quando usa do artifício de contar histórias, permite aos aprendizes uma experiência "vicária" para replicar em outras situações ou instâncias de aprendizado. (KAPP, 2012) Os elementos que tornam isso possível, segundo Kapp, são: os personagens; a ocorrência de "plot", acontecimentos na trama; a tensão gerada pela jornada do herói para contemplar os objetivos; e, para completar, a resolução da narrativa. "Esta estrutura simples pode ser usada para cenários de história baseados em jogos para ajudar os alunos a entender o que eles precisam fazer para ter sucesso em seu ambiente" (KAPP, 2012, p. 63. Tradução do autor)

Nagata (in ALVES, NERY, 2015) afirma que quando as crianças jogam videogames estão também apreendendo, mas por um formato de letramento múltiplo, mais amplo que ler e escrever. Para a autora (idem), cabe à escola e aos professores de literatura perceber e mediar o potencial educativo que os jogos podem proporcionar enquanto ambientes de aprendizagem aos jovens leitores.

Em relato acerca de tentativas infrutíferas para aproximar as turmas do ensino fundamental à literatura, Nagata (ibidem) percebeu no interesse dos alunos pelos jogos uma porta de motivação à literatura. Isso confirma uma problemática: "queremos que alunos leiam textos sobre experiências que eles nunca tiveram. Eles decodificam, mas não compreendem." (in ALVES, NERY, 2015, p.194) Houve muito mais facilidade e interesse dos alunos pela leitura de livros que apresentavam ligações ou traziam na íntegra as narrativas dos games que estavam acostumados a jogar em casa. Por outro lado, a literatura clássica, muito pouco contemplada pela industrial cultural, continuou sendo um desafio para o interesse dos jovens leitores, conforme o relato. (NAGATA, 2015 in ALVES, NERY, 2015)

As considerações apresentadas por Nagata (idem) são pertinentes ao afirmar que o ambiente de leitura não deve ser pensado apenas por um formato e ocorrer somente na escola, precisa se integrar e fazer parte do cotidiano dos leitores. Os jogos podem desempenhar ferramentas úteis nesse sentido. Também,"afirmar que os jovens são não leitores é enxergar o fenômeno de forma limitada.[...] Afinal, eles lêem, só não aquilo que a escola gostaria que lessem" Portanto, a relação entre jogos digitais, como o videogame, e a leitura pode ser potencialmente melhor explorada e refletida pelos mediadores de leitura: professores, escola e pais. Contudo, é um processo que exige cuidado. Não pode ocorrer "sem pensar nas suas devidas implicações para o processo de ensino e aprendizagem". (NAGATA, 2015 in ALVES, NERY, 2015, p.2001)

\section{Revisão bibliográfica Sistemática}

A Revisão Bibliográfica Sistemática (RBS) é um método apropriado para a compreensão do contexto em que se insere qualquer problema. A RBS tem por característica a abordagem exploratória e deve ser considerada, como afirma Conforto, Amaral e Silva (2011), como um passo inicial e como suporte para o desenvolvimento de pesquisas. São algumas das vantagens do método: consolidar evidências e resultados obtidos por pesquisas anteriores; identificar lacunas teóricas ou bases para estudos subsequentes; conhecer modelos teóricos, referencial teórico e procedimentos para auxiliar em um novo estudo. (CONFORTO, AMARAL, SILVA, 2011)

A RBS constitui uma espécie de "estudo secundário", já que depende das "entradas" de dados, resultantes de um processo sistematizado de busca, "estudos primários" e culmina na "saída" dos dados analisados. (idem) A condução destas etapas deve ser rigorosa e sistematizada, tornando possível rastrear o percurso tomado pelo investigador e os desdobramentos a partir dos resultados obtidos. 


\section{$16^{\circ}$ \\ ERGODESIGN USIHC CINAHPA}

$16^{\circ}$ Ergodesign - Congresso Internacional de Ergonomia e Usabilidade de Interfaces Humano Tecnológica: Produto, Informações Ambientes Construídos e Transporte

$16^{\circ}$ USIHC - Congresso Internacional de Ergonomia e Usabilidade de Interfaces Humano Computador

CINAHPA | 2017 - Congresso Internacional de Ambientes Hipermídia para Aprendizagem.
Conforto, Amaral e Silva (2011) propõem o modelo sistematizado de revisão bibliográfica RoadMap. O modelo destaca-se por prezar por um alto rigor científico, já que foi construído a partir do aprimoramento de outros três roteiros de RBS. O RoadMap tem seu início a partir da definição de um problema de pesquisa. (idem) No contexto aqui apresentado, esta pesquisa quer saber: como se aplicam os jogos digitais em livros infantis eletrônicos? A questão tem por objetivos compreender se existem estudos acerca da aplicação dos jogos digitais em $e$-books infantis e quais são as fronteiras e aplicações destes.

A partir de uma revisão assistemática, "dados primários" (CONFORTO, AMARAL, SILVA, 2011), foram encontrados alguns artigos e, a partir disso, journals de relevância no contexto dos livros infantis e jogos digitais. Podem ser destacados: Journal of Children's Literature publicado pelo Children's Literature Assembly (EUA); Journal of Child Language da Universidade de Cambridge (Reino Unido); International Journal of Children's Literature da Macquarie University (EUA) e Computers \& Education journal, da editora Elsevier. A partir da análise semântica das descrições, chamadas para envios de trabalhos e das palavras-chave dos artigos destes journals, foram definidos os conceitos e sinônimos para a geração das palavras de busca, strings. (Quadro 1)

\begin{tabular}{|l|l|}
$\begin{array}{l}\text { Strings em } \\
\text { português }\end{array}$ & Strings em inglês \\
\hline $\begin{array}{l}\text { Livro Infantil } \\
\text { ilustrado }\end{array}$ & "picture book" OR "picturebook" \\
\hline Livro eletrônico & $\begin{array}{l}\text { ebook OR "e-book" OR "electronic } \\
\text { book" OR "digital book" OR } \\
\text { "electronic publishing" }\end{array}$ \\
\hline Jogo Digital & "digital game" OR "game" \\
\hline
\end{tabular}

Quadro 1: Strings de busca. Fonte: do autor (2016)

O primeiro ciclo de busca, chamada aqui de piloto, ocorreu na base de periódicos da Capes/MEC, em 22/11/2016. A busca considerou a entrada de duas palavras-chave por vez, na correlação possível entre cada variação entre estas, no intuito de abranger o maior número de artigos dentro do escopo definido. Os critérios de inclusão e exclusão estão descritos a seguir (quadro 2).

\begin{tabular}{|c|c|}
\hline $\begin{array}{l}\text { Critérios para } \\
\text { Inclusão }\end{array}$ & Critérios para a exclusão \\
\hline $\begin{array}{l}\text { Artigos completos; } \\
\text { Revisão por pares; } \\
\text { Somente com } \\
\text { redação nos idiomas } \\
\text { português ou inglês; } \\
\text { Publicações a partir } \\
\text { do ano de } 2000\end{array}$ & $\begin{array}{l}\text { Material caracterizado como } \\
\text { resenha ou relatório; } \\
\text { Documentos sem dados } \\
\text { completos: nomes dos } \\
\text { autores, ano, título, } \\
\text { palavras-chave ou resumo; } \\
\text { Documentos não } \\
\text { duplicados. }\end{array}$ \\
\hline 988 Artigos & 424 Artigos totais \\
\hline
\end{tabular}

Quadro 2: Critérios de inclusão e exclusão. Fonte: do autor (2016)

O software utilizado para organização das referências e triagem dos arquivos duplicados foi o Mendeley. A seguir são descritas as fases de processamento e saída de dados.

\subsection{Processamento dos dados}

O processo de seleção dos 424 artigos, seguindo o modelo RBS RoadMap, ocorreu por 3 filtros. No primeiro, foram lidos os títulos, resumos e palavras-chave dos artigos. Todos os artigos que não abordavam os termos "e-book infantil" e "jogos", bem como as suas variações foram descartados, totalizando 28 artigos apenas. No segundo filtro foram lidos também a introdução e conclusões destes artigos restantes. Neste momento, foram prezados os que tratavam de livros infantis literários, na maior aproximação possível com o conceito de livros ilustrados, e que tratassem, mesmo que brevemente, de jogos digitais. Como resultado, foram selecionados no filtro 2 apenas 5, 0,5\% de artigos selecionados nesta etapa. Contudo, o filtro 3 que consiste na leitura integral dos textos e seleção qualitativa alinhada aos objetivos da RBS (CONFORTO, AMARAL, SILVA, 2011), revelou que apenas 3 


\section{$16^{\circ}$ \\ ERGODESIGN USIHC CINAHPA}

artigos tratavam dos jogos digitais em livros infantis eletrônicos, taxa de aproximadamente $0,3 \%$ de aproveitamento.

$\mathrm{O}$ resultado muito reduzido de pesquisas demonstrou a necessidade de um novo ciclo de buscas. Para esta nova coleta, os bancos de dados selecionados foram as plataformas com melhores resultados na RBS piloto: ACM Digital Library; ERIC, Institute of Education Science; IEEE Xplore, Digital Library. A nova RBS também teve como objetivo validar ou refutar a percepção originada a partir do estudo piloto, de que existe uma lacuna teórica nos estudos da aplicação de jogos no contexto dos livros infantis eletrônicos.

Com a entrada dos strings nos sistemas de buscas das plataformas, foi posto em dúvida se o termo "picturebook", para descrever livro ilustrado infantil, restringia muito os resultados obtidos. Portanto, foram adicionados dois novos strings, "literatura infantil" e "livro infantil". Os demais passos e filtros de triagem foram os mesmos obedecidos na RBS piloto. Os resultados obtidos estão sintetizados a seguir. (quandro 3)

\begin{tabular}{|c|c|c|c|c|c|}
\hline $\begin{array}{l}\text { String } \\
1\end{array}$ & \multicolumn{5}{|c|}{$\begin{array}{l}\text { picturebook OR (picture book) AND (digital } \\
\text { game) OR (game) AND e-book OR ebook OR } \\
\text { (electronic publishing) OR (electronic book) }\end{array}$} \\
\hline $\begin{array}{l}\text { String } \\
2\end{array}$ & \multicolumn{5}{|c|}{$\begin{array}{l}\text { (children's book) OR (children's literature) AND } \\
\text { (digital game) OR (game) AND e-book OR ebook } \\
\text { OR (electronic publishing) OR (electronic book) }\end{array}$} \\
\hline Fonte & String & Artigos & $\begin{array}{l}\text { Filtro } \\
1\end{array}$ & $\begin{array}{l}\text { Filtro } \\
2\end{array}$ & $\begin{array}{l}\text { Não } \\
\text { repetidos }\end{array}$ \\
\hline \multirow{2}{*}{$A C M$} & 1 & 626 & 48 & 9 & \multirow{2}{*}{9} \\
\hline & 2 & 125 & 12 & 5 & \\
\hline \multirow{2}{*}{ ERIC } & 1 & 16 & 8 & 2 & \multirow{2}{*}{2} \\
\hline & 2 & 3 & 2 & 1 & \\
\hline \multirow{2}{*}{ IEEE } & 1 & 15 & 5 & 0 & \multirow{2}{*}{1} \\
\hline & 2 & 5 & 3 & 1 & \\
\hline TOTAL & $1 e 2$ & 790 & 79 & 19 & 12 \\
\hline
\end{tabular}

Quadro 3: Processamento da RBS. Fonte: do autor (2016) $16^{\circ}$ Ergodesign - Congresso Internacional de Ergonomia e Usabilidade de Interfaces Humano Tecnológica: Produto, Informações Ambientes Construídos e Transporte

$16^{\circ}$ USIHC - Congresso Internacional de Ergonomia e Usabilidade de Interfaces Humano Computador

CINAHPA | 2017 - Congresso Internacional de Ambientes Hipermídia para Aprendizagem.
Após a seleção de artigos por meio dos filtros $1 \mathrm{e}$ 2 , a nova coleta demonstrou taxa de aproximadamente $1,5 \%$ de aproveitamento de artigos, 12 de um total de 79 , referentes à etapa 2 do processamento de dados. A taxa, um pouco superior em relação à pesquisa piloto, proporcionou 12 novos artigos para a leitura completa. Outro fator relevante diz respeito aos strings, apenas um artigo extra foi selecionado com a categoria que incluía nas palavras-chave "children's book"e "children's literature". Isso permite afirmar que o termo "picturebook", e suas derivações, é o mais apropriado e difundido cientificamente para caracterizar o formato de livros infantis tratados por esta pesquisa.

O filtro 3 consiste na leitura integral dos textos previamente selecionados, com o propósito de avaliar cada um de maneira minuciosa.

(CONFORTO, AMARAL, SILVA, 2011, p.10).

"Essa avaliação, utilizando os critérios de qualificação, será útil para priorizar os artigos e assim, identificar os mais relevantes para o estudo" (idem). Neste momento, conforme instruções de Conforto, Amaral e Silva (2011) foram decupados os critérios mais importantes a partir do problema e objetivos da pesquisa para a seleção e classificação final dos textos. Os critérios são descritos a baixo e, em seguida (quadro 4) se encontram resumidamente os resultados obtidos no filtro 3 de processamento da RBS RoadMap.

- Q1: O artigo tem como foco os livros ilustrados eletrônicos?

- Q2: O estudo trata de jogos no contexto dos $e$ books infantis?

- Q3: São estabelecidas considerações da aplicação de jogos digitais em $e$-books infantis?

- Q4: É analisada a presença de jogos em ebooks infantis?

- Q5:A análise demonstra rigosamente o processo de obtenção de dados?

\begin{tabular}{|c|c|c|c|c|c|c|c|c|c|}
\hline $\begin{array}{l}\text { Ba } \\
\text { se }\end{array}$ & $\mathbf{N}^{\circ}$ & Autor & Ano & & $\begin{array}{l}\mathbf{Q} \\
\mathbf{2}\end{array}$ & $\begin{array}{l}\mathbf{Q} \\
\mathbf{3}\end{array}$ & $\begin{array}{l}Q \\
4\end{array}$ & $\begin{array}{l}\mathbf{Q} \\
\mathbf{5}\end{array}$ & $\begin{array}{l}\text { To } \\
\text { tal }\end{array}$ \\
\hline U & 1 & Frederico et al. & 2016 & () & (;) & $\varnothing$ & & $\varnothing$ & 3 \\
\hline
\end{tabular}

Realização:

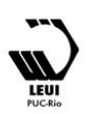


$16^{\circ}$ USIHC - Congresso Internacional de Ergonomia e Usabilidade de Interfaces Humano Computador

\begin{tabular}{|c|c|c|c|c|c|c|c|c|c|}
\hline & 2 & Sargeant & 2015 & () & (๑) & () & & $\varnothing$ & 8 \\
\hline & 3 & Homer et al. & 2014 & e) & $\odot$ & () & $\bullet$ & () & 10 \\
\hline & 4 & Morgan & 2013 & () & (). & $\varnothing$ & (-) & $\varnothing$ & 4 \\
\hline & 5 & Kao et al. & 2013 & (ब) & (). & (-) & $\varnothing$ & ๑) & 6 \\
\hline & 6 & Cesário et al. & 2016 & () & $\varnothing$ & $\varnothing$ & $\varnothing$ & $\varnothing$ & 2 \\
\hline & 7 & $\begin{array}{l}\text { Figueiredo e } \\
\text { Sylla }\end{array}$ & 2014 & - & ๑ & (-) & (i) & $\varnothing$ & 6 \\
\hline 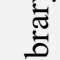 & 8 & Sargeant & 2014 & () & $\varnothing$ & $\varnothing$ & $\varnothing$ & $\varnothing$ & 2 \\
\hline $\bar{\sigma}$ & 9 & Schafere et al. & 2013 & 인 & $\varnothing$ & $\varnothing$ & $\varnothing$ & $\varnothing$ & 2 \\
\hline .0.0 & 10 & Pinto et al. & 2013 & () & () & $\varnothing$ & $\varnothing$ & $\varnothing$ & 3 \\
\hline$\sum_{<}^{\sum}$ & 11 & $\begin{array}{l}\text { Colombo e } \\
\text { Landoni }\end{array}$ & 2011 & (-) & $\varnothing$ & $\varnothing$ & $\varnothing$ & $\varnothing$ & 1 \\
\hline & 12 & Landoni & 2010 & () & $\varnothing$ & $\varnothing$ & $\varnothing$ & ()) & 3 \\
\hline & 13 & Cardem & 2008 & 0 & $\varnothing$ & $\varnothing$ & $\varnothing$ & $\varnothing$ & 2 \\
\hline & 14 & Wagner & 2006 & (2) & ๑ & e & $\varnothing$ & $\varnothing$ & 4 \\
\hline & 15 & Evain e Marco & 2016 & ().) & $\varnothing$ & $\varnothing$ & $\varnothing$ & $\varnothing$ & 1 \\
\hline$\frac{x}{I}$ & 16 & Ciampa & 2012 & 우 & (-) & e & () & (); & 6 \\
\hline 弐 & 17 & Suitsu et al. & 2016 & (2) & & $\varnothing$ & $\varnothing$ & $\varnothing$ & 2 \\
\hline
\end{tabular}

estabelecidos e por isso foram desconsiderados na análise de dados a seguir.

\subsection{Fase 3-Saída dos dados}

Paralelamente a leitura e interpretação minuciosa de cada artigo (filtro 3), foram realizadas anotações para cada artigo no formato de formulário, como recomenda Conforto, Amaral e Silva (2011): datas das publicações; resumo das principais contribuições; conceitos-chave apresentados ou citados; métodos de pesquisa e análise utilizados; nome do periódico, dos co-autores, instituições e das principais referências. Estes dados foram analisados na etapa seguinte, fase 3 do modelo RBS RoadMap. Contudo, os dados mais prezados por esta pesquisa tratam-se das considerações apersentadas pelos estudos acerca das fronteiras e aplicações dos jogos digitais em $e$-books infantis.

Os 5 artigos selecionados foram publicados entre os anos de 2010, período em que era lançado o aparelho Ipad (SARGEANT, 2015), até 2016, ano de realização deste estudo. Não por acaso, 3 dos artigos discutem ou ao menos citam este $e$-reader em seus estudos. Kao et al. (2016) elegeram o ipad como suporte para um experimento com crianças na intenção de descobrir relações entre o engajamento de leitura e a presença de recursos de interação em $e$-books infantis. Sargeant (2015), como já visto anteriormente, evidencia o aparelho ipad como o propiciador do surgimento dos livros aplicativos, pois proporciona recursos avançados de interação multimídia. Figueiredo e Sylla (2015)

Legenda:

( $)$ Atende o critério $=2$ pontos; demonstram como o jogo com elementos físicos (-) Atende parcialmente o critério $=1$ ponto; $\varnothing$ Não atende o critério $=0$ pontos.

Quadro 4: Filtro 3 da RBS. Fonte: do autor (2016)

Após a leitura análise sistemática de cada texto foi decidido que apenas os artigos com pontuação igual ou maior que 6 apresentaram contribuições aos objetivos da RBS. É importante salientar que os 17 artigos identificados e lidos integralmente apresentaram análises, debates ou investigações bastante interessantes. Contudo, muitos deles não contemplaram parte importante dos critérios pode ser incorporado na experiência de leitura na tela do aparelho. Estas observações permitem afirmar que, a partir do surgimento do ipad, o formato de livro infantil app tem sido, senão o principal, um dos produtos multimídia com maior destaque na convergência entre a literatura infantil e os jogos digitais. Contudo, os estudos de Homer et al. (2014) já apontam resultados muito atraentes em um sentido inverso, na aplicação da literatura infantil em consoles como o Kinect, aparelho da Microsoft, lançado inicialmente para jogos com captura de movimento.

Quanto aos métodos utilizados pelos artigos
Realização:

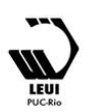




\section{$16^{\circ}$ \\ ERGODESIGN USIHC CINAHPA}

selecionados, Homer et al. (2014) ganham destaque devido ao rigor científico, variedade de ferramentas empreendidas e sistematização do processo de coleta e análise. No estudo, os autores (HOMER et al., 2014) exercem a avaliação dos potenciais de aprendizagem e letramento de "jogos digitais de leitura" - digital reading games, definição criada por eles -. Para isso utilizam o livro ilustrado infantil Children Make Terrible Pets (Brown, 2010) em 3 modalidades diferentes de leitura: uma delas a partir do livro impresso e as outras a partir da versão do mesmo livro em formato de jogo Kinect, sendo que uma destas exigia o uso de movimentos gestuais da criança para a leitura.

O experimento foi aplicado com 3 grupos similares, 13 crianças cada, estimulados de forma diferente. É importante salientar que todos os grupos contaram com a mediação de leitura de um adulto e, no experimento com o console kinect, com a ajuda da equipe de pesquisadores para auxiliar na captura de movimentos e ensinando os gestos requeridos. Um grupo de crianças foi submetido à leitura do livro ilustrado impresso. $\mathrm{O}$ outro exerceu a leitura por meio do jogo Kinect sem atividades que exigiam gestos. Por fim, o terceiro grupo fez a partir do jogo com o uso de movimentos corporais. (HOMER et al., 2014) A amostragem dos testes contou com 39 crianças (22 meninos e 17 meninas) com idades entre 5 a 7 anos, estudantes do jardim de infância (21) e da primeira série (18) de três escolas norteamericanas. Todas as crianças eram fluentes em inglês e dispunham de um sistema de ensino e alfabetização similar, iniciado desde o jardim de infância, e boa parte pertencia a faixas socioeconômicas minoritárias (aproximadamente 60\%). A investigação contou com um pré-teste, onde ocorreram entrevistas com cada criança, no estilo de conversação, para conhecer as práticas e preferências de leitura e de jogo. Também foram coletados dados referentes ao letramento, tornando possível a comparação ao final da pesquisa.

(HOMER et al., 2014)

O pós-teste também ocorreu no formato de entrevistas orais, como uma conversa com as crianças e proporcionou, dentre alguns itens, $16^{\circ}$ Ergodesign - Congresso Internacional de Ergonomia e Usabilidade de Interfaces Humano Tecnológica: Produto, Informações Ambientes Construídos e Transporte

$16^{\circ}$ USIHC - Congresso Internacional de Ergonomia e Usabilidade de Interfaces Humano Computador

CINAHPA | 2017 - Congresso Internacional de Ambientes Hipermídia para Aprendizagem. medir: a aquisição de novo vocabulário em relação ao pré-existente; a compreensão das definições, significados, de novas palavras oportunizadas pela história; a compreensão da narrativa e identificação dos personagens. Também foi exercido um autorelato das crianças quanto ao interesse de leitura por meio de um teste de medição das emoções (carinhas felizes, neutras ou tristes). (HOMER et al., 2014)

As sessões também foram gravadas e oportunizaram aos pesquisadores (HOMER et al., 2014) avaliar: o comportamento das crianças nas tarefas; a utilização e confusão nos gestos; as necessidades originadas, dentre outros fatores relevantes.

Sargeant (2015), por outro lado, apresenta uma revisão do estado da arte das pesquisas relacionadas a livros ilustrados eletrônicos. Com base na literatura estabelece definições dos modelos e formatos $e$-books ilustrados e, a partir disso, exerce análises descritivas simplificadas das características de 6 obras.

Figueiredo e Sylla (2014) se limitam apenas a apresentar características do projeto Magnetic Appcessories, uma estação mista que integra leitura digital e jogo físico. Trata-se um suporte impresso que integra um aparelho Ipad e permite a interação entre personagens materializados no formato de peças de madeira. Conforme a interação da criança com os personagens em frente à tela do tablet, sensores eletrônicos acionam narrativas condizentes com as peças. Apesar de um produto interessante, as autoras (FIGUEIREDO, SYLLA, 2014) afirmam que este ainda se encontra em desenvolvimento e não apresentam nenhum resultado acerca de sua utilização.

Ciampa (2012), na investigação da motivação e experiência de leitura de livros eletrônicos infantis, acompanhou alunos entre 5 e 6 anos de uma escola primária de Ontário, no Canadá. Os alunos, 4 meninas e 4 meninos, participaram de dez sessões, aproximadamente 25 minutos, de leitura de livros eletrônicos online em computadores. Os dados qualitativos foram coletados por diários de observação dos alunos e entrevistas por

Realização:




\section{$16^{\circ}$ \\ ERGODESIGN USIHC CINAHPA}

questionários, que também incluíram os professores e pais dos alunos. A pesquisa avaliou aspectos de leitura, apesar de não delimitar necessariamente os $e$-book pelo formato literário livro ilustrado. Os livros continham jogos de aprendizagem, que propunham desafios, contudo foram apenas mais um dos recursos compreendidos pela pesquisa. $\mathrm{O}$ que torna a as contribuições do estudo (CIAMPA, 2012) circunstancialmente pouco expressivas ao problema aqui investigado

Kao et al. (2013) traçaram uma investigação com o propósito de verificar diferenças no efeito de motivação para a leitura e aprendizagem de acordo com a presença de interação em $e$-books infantis. A pesquisa foi realizada com a observação e medição de dados de 40 alunos de quarta série de uma escola de Taiwan, China. Para isso, a pesquisa comparou o processo de leitura de um livro ilustrado para tablet, projetado por meio de uma pesquisa de design, em dois formatos eletrônicos: um com baixa interatividade, incluindo apenas narração e botões interativos simples, como virar a página; o protótipo desenvolvido com maior interação apresentava orientações extras, acionadas no livro proporcionavam alertas no formato de perguntas e avisos e possibilitava troca de informações por perguntas e respostas dos feedbacks dos leitores. Contudo, os autores (Kao et al. 2013), deixam de fora dos escopo os jogos enquanto recursos de interação.

\section{Fronteiras e aplicações dos jogos digitais em e-books infantis}

As pesquisas de Kao et al. (2013) e Sargeant (2015) classificam os jogos digitais como recursos interativos presentes em e-books infantis. Todavia, Kao et al. (2013), apoiadas no referencial teórico adotado, descartam a utilização de jogos digitais afirmando que não são "benéficos para a compreensão do conteúdo da história, porque a informação visual distrairia os alunos dos textos." (KAO et al.,2013, p. 57. Tradução do autor)

Já para Sargeant (2015), a aplicação de recursos interativos, especialmente jogos, pode promover a motivação dos usuários de livros eletrônicos, como tambem provocar um "play mode" e distrair as $16^{\circ}$ Ergodesign - Congresso Internacional de Ergonomia e Usabilidade de Interfaces Humano Tecnológica: Produto, Informações Ambientes Construídos e Transporte

$16^{\circ}$ USIHC - Congresso Internacional de Ergonomia e Usabilidade de Interfaces Humano Computador

CINAHPA | 2017 - Congresso Internacional de Ambientes Hipermídia para Aprendizagem. crianças na atividade da leitura. A autora (idem) avalia positivamente os recursos interativos das atividades lúdicas apresentadas pelo livro "The Fantastic Flying Books of Mr. Morris Lessmore" (2011). Entretanto, salienta que às ações que "permitem brincar com o ambiente narrativo" neste livro, por exemplo, são vagamente conectadas à narrativa, apesar de privilegiarem atividades baseadas na compreensão da história.

Para Sargeant (2015) os livros aplicativos são estruturados na junção das áreas do design editorial, design de jogos e filmes de animação. Contudo, nas obras eletrônicas infantis as atividades lúdicas mais comumente encontradas são quebra-cabeças e enigmas, pois envolvem o leitor de uma forma mais discreta. Na verdade, "jogar" estas atividades não as caracteriza enquanto jogos, já que são operações que escondem uma solução pré-programada e o jogador exerce tentativas limitadas de resolvê-las dentro de escolhas pré-estabelecidas.

(SARGEANT, 2015) O livro aplicativo "Red Riding Hood" (2013 apud SARGEANT, 2015), por exemplo, permite aos leitores escolher diferentes rotas no percurso de Chapeuzinho Vermelho à casa da Vovó. Cada caminho selecionado tem impacto sobre a narrativa, revelando um conjunto de acontecimentos préprogramados para cada escolha. Apesar do recurso parecer interessante, não chega a ser propriamente um jogo, já que os jogos são mais estruturados e flexíveis ao usuário. (SARGEANT, 2015) Os jogos formais envolvem regras e métodos de pontuação e proporcionam aos jogadores formas mais livres de atingir metas e objetivos distintos. (KAPP, 2012).

Já o livro app "The Heart and the Bottle"(2011 apud SARGEANT, 2015) proporciona recursos que permitem o usuário fazer um desenho em áreas da tela que em seguido é exibido em uma cena subsequiente da narrativa. Para Sargeant (2015, p.462) esta é "uma atividade de jogo não estruturada que permite aos usuários contribuir para o conteúdo visual do aplicativo."

Toda atividade lúdica ou recurso interativo, incluindo jogos, devem ocorrer de forma a manter a integridade da narrativa principal do livro.

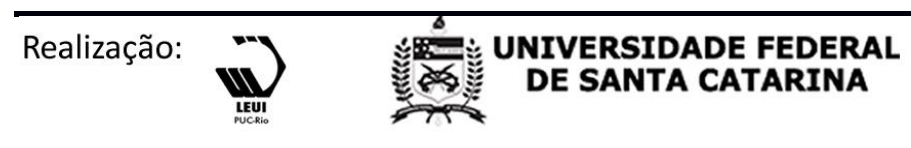

DE SANTA CATARINA Q⿱日一⿻日土 


\section{$16^{\circ}$ \\ ERGODESIGN USIHC CINAHPA}

(SARGEANT, 2015) Para a autora (idem), há muitas maneiras pelas quais o design do $e$-book pode propor atributos que mantenham conexão com as histórias. "Thus How Far is Up?"(2014) e "The Monster at the End of this Book" (2011) foram projetados com recursos interativos que mesclam jogos de modo a reforçar a leitura, inclusive propondo desafios que aumentam o engajamento do leitor na história a cada nova página.

Ciampa (2012) afirma bons resultados da inclusão de jogos educacionais como recursos de feddback, na forma de tarefas de reforço para a compreensão da história. O que proporcionou aumento no engajamento e desempenho de leitura em livros eletrônicos pelos alunos acompanhados na pesquisa. Por outro lado, os mesmos alunos apresentaram problemas de atenção no modelo regular de leitura, do livro impresso. Além demonstrarem ansiedade para responder um feedback imediato assim que aprendiam alguma coisa, as crianças "estavam muito menos entusiasmadas com a perspectiva de voltar a tentar reaprender algo que elas já fizeram"(CIAMPA, 2012, p. 38)

Na pesquisa com as três diferentes formas de leitura, Homer et al. (2014) afirmam que as crianças, dos três grupos analisados em suas pesquisas, apresentaram melhorias em todas as medidas de leituras realizadas e resultados bastante similares. Para os autores, isso se dá principalmente devido à técnica leitura dialógica empregada, que consiste em um diálogo entre o mediador, um adulto leitor, e as crianças. Esse modelo de leitura demonstrou potencializar os resultados a partir do livro impresso, do jogo comum ou da versão do Kinect com gestos. Isso também indicou que os jogos digitais de leitura não se configuraram como atividades que causaram distração.

Os resultados obtidos por Homer et al. (2014) também indicam que a leitura de livros em um sistema de jogo digital baseado em gestos pode ser uma atividade instigante para as crianças. Também é possível afirmar a partir das contribuições que o incremento de atividades que envolvam jogos $16^{\circ}$ Ergodesign - Congresso Internacional de Ergonomia e Usabilidade de Interfaces Humano Tecnológica: Produto, Informações Ambientes Construídos e Transporte

$16^{\circ}$ USIHC - Congresso Internacional de Ergonomia e Usabilidade de Interfaces Humano Computador

CINAHPA | 2017 - Congresso Internacional de Ambientes Hipermídia para Aprendizagem.

durante a leitura, quando bem projetadas, podem apoiar não só a aquisição de linguagem, alfabetização e desenvolvimento da cognição visual como também estimular o sistema psicomotor infantil.

Portanto, não apenas o jogo digital, mas todo e qualquer recurso interativo ou multimídia, deve ser planejado para manter o interesse, proporcionar o engajamento, na leitura e não apenas ser utilizado como instrumento de motivação desalinhada dos objetivos literários. "Então ele pode ter um efeito benéfico que é comparável ao engajamento na leitura dialógica com um adulto" (HOMER et al. 2014), contudo não quer dizer que substitua a presença de um adulto leitor. Inclusive, mesmo durante os jogos digitais de literatura, que propunham recursos automáticos de leitura e intuitivamente auxiliavam os leitores à navegação, a presença de um adulto se fez indispensável. As crianças, mesmo nestes casos, precisam de instruções e apoio ao processo de decodificação de informações.

Outro aspecto importante pontuado por Homer et $a l$. (2014) é a incorporação das atividades propostos pelos livros com jogos de gestos ao repertório cognitivo dos leitores iniciantes. A multimodalidade de estímulos pode proporcionar experiências vicárias que reforçam a aprendizagem e promovem a incorporação de ações que podem ser transferidas para outras atividades cotidianas da vida da criança, inclusive para o momento tradicional de leitura. Nessa condição, a pesquisa demonstra o contrário do que foi percebido por Ciampa (2012), acerca da desmotivação na leitura de livros impressos quando a criança passa por experiências a partir da leitura de e-books. Esta questão pode ser considerada como um aspecto que merece ser melhor estudado e analisado em pesquisas futuras, já que ambos os autores (HOMER et a.l, 2014; CIAMPA, 2012) demonstram algumas variáveis e fragilidades em suas pesquisas, como o caso da necessidade de um número mais diversificado de obras eletrônicas a serem analisadas por maiores amostragens de crianças.

Por fim, os autores, exceto Kao et al. (2013),

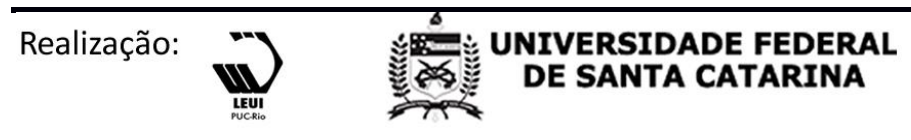

DE SANTA CATARINA Q⿱日一⿻日土 


\section{$16^{\circ}$ \\ ERGODESIGN USIHC CINAHPA}

$16^{\circ}$ Ergodesign - Congresso Internacional de Ergonomia e Usabilidade de Interfaces Humano Tecnológica: Produto, Informações Ambientes Construídos e Transporte

$16^{\circ}$ USIHC - Congresso Internacional de Ergonomia e Usabilidade de Interfaces Humano Computador

CINAHPA | 2017 - Congresso Internacional de Ambientes Hipermídia para Aprendizagem. consideram que os jogos, de algum modo ou de outro, são proveitosos para promover estratégias de engajamento de leitura, alfabetização e desenvolvimento cognitivo. Não apenas os $e$ books, mas os próprios jogos digitais podem proporcionar interessantes plataformas de promoção da leitura infantil. (FIGUEIREDO, SYLLA, 2014; HOMER et a.l, 2014) Contudo, todas as pesquisas concordam que jogos ou qualquer outro atributo só deve ser incrementado ao livro infantil de forma cuidadosa, estrategicamente alinhados à narrativa e visando qualificar ainda mais os ambientes de narrativa e aprendizagem.

\section{Referências Bibliográficas}

NAGATA, Aline A. Sobre Livros E Games: Fugindo das Armadilhas do Óbvio. In: ALVES, Lynn; NERY, Jesse. (Orgs.) Jogos Eletrônicos, mobilidades e Educações: Trilhas em construção. Salvador : EDUFBA, 2015.

BEDERSON, Benjamin B.; QUINN, Alex; DRUIN, Alisson. Designing the Reading Experience for Scanned Multi-lingual Picture Books on Mobile Phones. In: Joint Conference on Digital Libraries, N. 15, Vol. 1. Austin, USA, Jun. 2009.

CIAMPA, Katia. Reading in the Digital Age: Using Electronic Books as a Teaching Tool for Beginning Readers. In: Canadian Journal of Leraning ad Technology. N. 2, Vol. 38. 2012

CONFORTO, E. C.; AMARAL, D. C.; SILVA, S. L. Roteiro Para Revisão Bibliográfica Sistemática: Aplicação no Desenvolvimento de Produtos e Gerenciamento de Projetos. In: $\mathbf{8}^{\mathbf{o}}$. Congresso Brasileiro de Gestão de Desenvolvimento de Produto - CBGDP. Anais. Porto Alegre: IGDP, 2011.

FIGUEIREDO, Ana C.; SYLLA, Cristina; BRANCO, Pedro; ZAGALO, Nelson. Merry Go Round: A Physical, Virtual, Physical... Toy. In: Proceedings of the 11th Conference on

\section{Advances in Computer Entertainment} Technology. N.1, Vol. 59. NY, USA. Nov, 2014.

FIPE/USP. Pesquisa sobre a produção e vendas do setor editorial brasileiro. Ano base 2014 . Disponível em: <http://goo.gl/qThpsl>.Acessado em 01/05/2016.

FLATSCHART, Fábio. Livro Digital etc. Rio de Janeiro: Brasport, 2014.

FREDERICO, Aline. O Futuro do Leitor ou o Leitor do Futuro: o Livro Infantil Interativo e os Letramentos Múltiplos. In Cadernos de Letras da UFF Dossiê: A crise da leitura e a formação do leitor. N. 52, 2016

The Construction of Meaningin Three Fairy-

TaleEnhanced Electronic Picturebooks. In:

Children's Literature, Technology and

Imagination. University of Padua, Italy, 2013.

HALL, Andrew. Fundamentos Essenciais da Ilustração. São Paulo, SP: Rosari, 2012.

HOMER, Brunce D.; KINZER, Charles K.; PLASS, Jan; LETOURNEAU, Suasan; HOFFMAN, Dan; BROMLEY, Meagan; HAYWARD, Elizabeth; TURKAY, Selen; KORNAK, Yolanta. Moved to learn: The effects of interactivity in a Kinect-based literacy game for beginning readers. In: Computers \& Education journal, N.74. Ed. Elsevier, 2014.

HUIZINGA, Johan. Homo Ludens. O jogo como elemento da Cultura. São Paulo: Perspectiva, 2007.

KAPP, Karl M. The gamification of learning and instruction: game-based methods and strategies for training and education. San Francisco: Pfeiffer, 2012.

KAO, Gloria Yi-Ming; Tsai; Chin-Chung; Liu , Cheng-Han. The relative effectiveness of digital game-based learning types in English as a foreign language setting: A meta-analysis. In: Computers \& Education, Vol. 10. Ed. Elsevier. 2016.

LAROSSA, J. La experiencia de la lectura. In:
Realização:

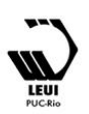




\section{$16^{\circ}$}

ERGODESIGN USIHC CINAHPA $16^{\circ}$ Ergodesign - Congresso Internacional de Ergonomia e Usabilidade de Interfaces Humano Tecnológica: Produto, Informações Ambientes Construídos e Transporte

$16^{\circ}$ USIHC - Congresso Internacional de Ergonomia e Usabilidade de Interfaces Humano Computador

CINAHPA | 2017 - Congresso Internacional de Ambientes Hipermídia para Aprendizagem.
Estudios sobre lectura y formación. Barcelona: Laertes, 1996.

\section{LINDEN, S. VAN DER. Para ler o livro \\ ilustrado. São Paulo: Cosac Naify, 2011.}

MELLO, G. Desafios para o setor editorial brasileiro de livros na era digital. In Economia da Cultura. BNDS Setorial, 2012.

MORAES, Giselly L. Do livro ilustrado ao aplicativo: reflexões sobre multimodalidade na literatura para crianças. In: Estudos de Literatura Brasileira Contemporânea. N.46, Brasília, July/Dec, 2015

NECYK, B. J. Texto e imagem: um olhar sobre o livro infantil contemporâneo. Dissertação (Mestrado) Programa de PósGraduação em Design do Departamento de Artes\&Design do Centro de Teologia e Ciências Humanas da PUC-Rio. Rio de Janeiro, 2007.

NIKOLAJEVA, M.; SCOTT, C. Livro Ilustrado: palavras e Imagens. São Paulo: Cosac Naify, 2011.

OLIVEIRA, Ieda. (Org). O que é qualidade em ilustração no livro infantil e juvenil: com a palavra o ilustrador. São Paulo: DCL, 2008.

SALISBURY, Martin; STYLES, Morag. Livro infantil ilustrado: a arte da narrativa visual. São Paulo: Rosari, 2013.

SARGEANT, Betty. What is an ebook? What is a Book App? And Why Should We Care? An Analysis of Contemporary Digital Picture Books. In: Children's Literature in Education, 46:454466. Springer Science, 2015.

SMEETS, D. J. H; BUS, A. G. The interactive animated e-book as a word learning device for kindergartners. Applie Psycholinguistics, N.4, Vol.36, 2012

TEIXEIRA, Deglaucy; Gonçalves, Berenice S. Interatividade e imersão em narrativa digital de $e$ book interativo infantil. In: 7 th Information Design International Conference. Blucher Design Proceedings. N. 2, V.2. Setembro, 2015

\section{Agradecimentos}

Agradecemos ao Departamento de Expressão Gráfica da Universidade Federal de Santa Catarina (EGR/UFSC) por apoiar o primeiro autor deste texto ao aprimoramento profissional em nível de doutorado, possibilitando assim maior dedicação à pesquisa. 